\title{
RESPONSE TO INTRADERMAL AUTOLOGOUS PLATELET RICH PLASMA INJECTION IN REFRACTORY DERMAL MELASMA: REPORT OF TWO CASES
}

\author{
Yew $\mathrm{CH}^{1}$, Ramasamy $\mathrm{TS}^{2}$, Amini $\mathrm{F}^{1}$ \\ 1 School of Healthy Aging, Medical Aesthetics and Regenerative Medicine, Faculty of Medicine and Health Science, UCSI \\ University, Kuala Lumpur \\ 2 Department of Molecular Medicine, Faculty of Medicine, University of Malaya, Kuala Lumpur
}

\author{
Correspondence: \\ Farahnaz Amini \\ School of Healthy Aging, Medical Aesthetics and Regenerative Medicine; UCSI University KL Campus, No.1; Jalan Menara \\ Gading; UCSI Heights (Taman Connaught), Cheras, 56000 Kuala Lumpur, Malaysia. \\ Email:farahnaz@ucsiuniversity.edu.my \\ Tel: +603 91018880 (Extn: 3752) \\ Fax: +60391317044
}

\begin{abstract}
Refractory dermal melasma is resistant to conventional treatment. Platelet rich plasma (PRP) may help to reduce the pigmentation of melasma. We present a case report on the clinical outcome of 2 patients with melasma, given PRP, as an adjunct therapy. PRP was administered at a monthly interval for 2 sessions in combination with a monthly Q-switched Nd Yag laser treatment and topical alpha arbutin application. A modified melasma area and severity index (MASI) was evaluated by two dermatologists who were blinded. At the follow up on the $3^{\text {rd }}$ months, the MASI score was reduced by mean $33.5 \%$ for case 1 and $20 \%$ for case 2 . There were no clinical complications for case 1 . However recurrence of melasma was noted in case 2 by a worsening of the MASI score mean to $53 \%$ at the sixth months follow up. In conclusion, intradermal PRP injection as an adjunct to the conventional treatment of melasma presented with differing results in two cases.
\end{abstract}

Keywords: Alpha arbutin, Melasma, Platelet rich plasma, PRP, Q-switched Nd Yag laser

\section{Introduction}

Melasma is a chronic pigmentary skin disease. It is diagnosed by the detection of brown or gray patches on sun exposed areas of the face including the forehead, nose, and over the malar and mandibular region (1). It is commonly seen in women especially those with a darker skin tone with Fitzpatrick photo types III through VI. Melasma can be histologically classified into three types, according to the deposition of the hyperactive melanocytes, as the epidermal, dermal or a mixed type involving both the epidermal and dermal layers. The prevalence of melasma in the general population varies according to geographical location and race. Prevalence of $8.8 \%$ in Hispanic women, $40 \%$ in South East Asian women and $20 \%$ in men have been reported $(2,3)$.

The exact pathogenesis of melasma is not fully understood. Two theories have been reported in regards to the hyperpigmentation of melasma, an increased synthesis of melanin by melanocytes resulting in a melanocytic hyperpigmentation, or an increase in the number of melanocytes, forming a melanocytic hyperpigmentation (4). According to the study by Kang et al. (5) there were no significant differences between the number of Langerhans cells, collagen and basement membrane appearance in normal and melasma skin. But melanocytes obtained from melasma skin contained more cytoplasmic organelles such as dendrites, mitochondria, Golgi bodies, and rough endoplasmic reticulum compared to the perilesional normal skin. The study suggested that in melasma affected skin, the number of melanocytes were not increased but were biologically hyperactive and produced more melanin.

The risk factors associated with melasma are ultra violet (UV) radiation, pregnancy and hormonal therapies with oral contraceptive pill and with, thyroid hormone supplements, phototoxic drugs and anticonvulsant medications (1, 6-7). 
Some studies have shown that the exposure to UV radiation over the cutaneous vasculature and hormonal changes are risk factors for melasma $(5,8-11)$.

Management of melasma is challenging for both the physicians and the patient. Treatment are mainly designed to target key factors in the synthesis of melanin (12). First line treatment target pigment production by using a broad spectrum sunscreen in combination with topical agents such as keratinocyte turnover stimulator (retinoids), tyrosinase inhibitor (hydroquinone, azelaic acid, arbutin), melanosome transfer inhibitor (retinoids, soybean trypsin inhibitor), and chelation of copper (kojic acid, ascorbic acid). Second line treatment are chemical based peeling such as glycolic acid peels starting at $30 \%$ for every $4-6$ weeks (13-14). If the outcome of the second line treatments is not satisfactory then the third line treatment-would be considered which includes light based and fractional laser therapies. Recently the subthermolytic Q-switched Nd Yag laser therapy has been widely used because of its efficacy and safety even in Asian patients with darker skin tone (15). Although subthermolytic Q-switched $1064 \mathrm{~nm}$ Nd Yag laser therapy has shown promising results, this treatment would require multiple sessions on a weekly basis, which would burden the patients $(16,17)$. In addition, there are some reports of confetti-like hypopigmentation occurring after multiple treatment sessions $(18,19)$. In general, epidermal type melasma respond well to these conventional treatment (20). However, many of the melasma patients who present at the clinic have mixed type melasma which is difficult to treat due to its recurring nature and post-inflammatory pigmentation alteration after treatment $(16,21)$.

A pilot study on Korean subjects demonstrated an improvement in the melanin index of patients treated with PRP in combination with ablative fractional photothermolysis (22). As there is no randomized controlled study using PRP therapy for treating melasma, we undertook a pilot study to evaluate the effectiveness of PRP in treating melasma.

\section{Case Presentation}

Subject 1: She was a 42 year old female with a Fitzpatrick skin type IV. She had no known medical illness, did not take any oral contraceptive pill (OCP) and was not undergoing hormone replacement therapy (HRT). There was no significant aesthetic and surgical history. She came with the complaint of having a few patches of brown pigmentation on both her cheeks for about 10 years, but worsening for the past few years. Clinical examination showed that a few patches of brown pigment macule on both malar and temporal area were suggestive of a mixed melasma. Three to four small bluish brown macules on her cheeks might be Hori nevus. Initially she was given a depigmenting agent Pro-heal Serum (IS Clinic Products) which contains topical alpha arbutin for a twice daily application and she was also started on a $1064 \mathrm{~nm}$ Q-switched Nd Yag laser (Conbio RevLite) at $10 \mathrm{~Hz}$, spot size of $8 \mathrm{~mm}$, at the fluence of $2.0-2.3 \mathrm{~J} / \mathrm{cm} 2$ for two passes then spot size of $6 \mathrm{~mm}$ at $3.0-3.6 \mathrm{~J} / \mathrm{cm} 2$ for 2 to 4 passes in at a monthly interval from June 2012 to November 2012. However her melasma pigmentation was not improving and an intradermal injection of PRP as adjunctive therapy was added and started in December 2012 and administered at a monthly interval.

Subject 2: She was a 51 year old female with a Fitzpatrick skin type $V$. She had no known medical illness and was not on any OCP, HRT, anti-convulsant or thyroid medications. There was no significant aesthetic and surgical history. She was concerned over the large patches of brown pigmentation on both her cheeks for about 15 years. A clinical assessment showed that there were irregular brown pigment macules over both malar areas with telangiectasia suggestive of a mixed melasma. She had been treated with laser at another centre with no improvement. She was given topical Pro-heal Serum (IS Clinic Products) which contains alpha arbutin for a twice daily application, and she was started on 1064nm Q-switched Nd Yag laser (Conbio RevLite) at $10 \mathrm{~Hz}$, spot size of $8 \mathrm{~mm}$ at the fluence of $1.8-2.1 \mathrm{~J} / \mathrm{cm} 2$ for 2 passes then spot size of $6 \mathrm{~mm}$ at $2.8-3.1 \mathrm{~J} / \mathrm{cm} 2$ for 2 to 4 passes at a monthly interval from June 2013 to September 2013. In view of her concern of dry skin with fine lines and telangiectasia, an intradermal injection of PRP was offered for the pigmentation area as an adjunctive therapy, together with the $Q$-switched laser session at a monthly interval from June 2013.

In this case study, assessment of efficacy of treatment and the severity of the melisma was done using a modified melasma area and severity index (MASI) scoring (Figure 1) by two blinded dermatologists.

Subject 1 showed a remarkable improvement of the MASI score after a single session of PRP therapy (Figure 2). The mean percentage of MASI score improvement was about $33.5 \%$ at the first follow up on the third month (Appendix 1). A further improvement was noted with a reduction of MASI mean score to about $26.4 \%$ at the follow up on the sixth month. Subject 2 also showed improvements of the severity of melasma with the mean reduction of MASI score by approximately $20 \%$. However, the rebound hyperpigmentation was noted by two blinded dermatologists in this case during 6 months follow up, with the mean increase of MASI score for about 53\% (Figure 3). Details of MASI scoring for each patient from two assessors can be found in appendix 1. A comparison of mean MASI scores given by 2 assessors for case $1 \& 2$ is depicted in Figure 4.

The side effects and complications observed in this case study were minimal and tolerable to the subjects. Both subjects experienced mild erythema, oedema and small needle prick mark bruises for the first few days after the PRP therapy. The erythema and oedema were resolved within one to two days. The bruises lasted slightly longer, for about 4 to 5 days as if the injections of the PRP had injured some of the small blood vessels. 


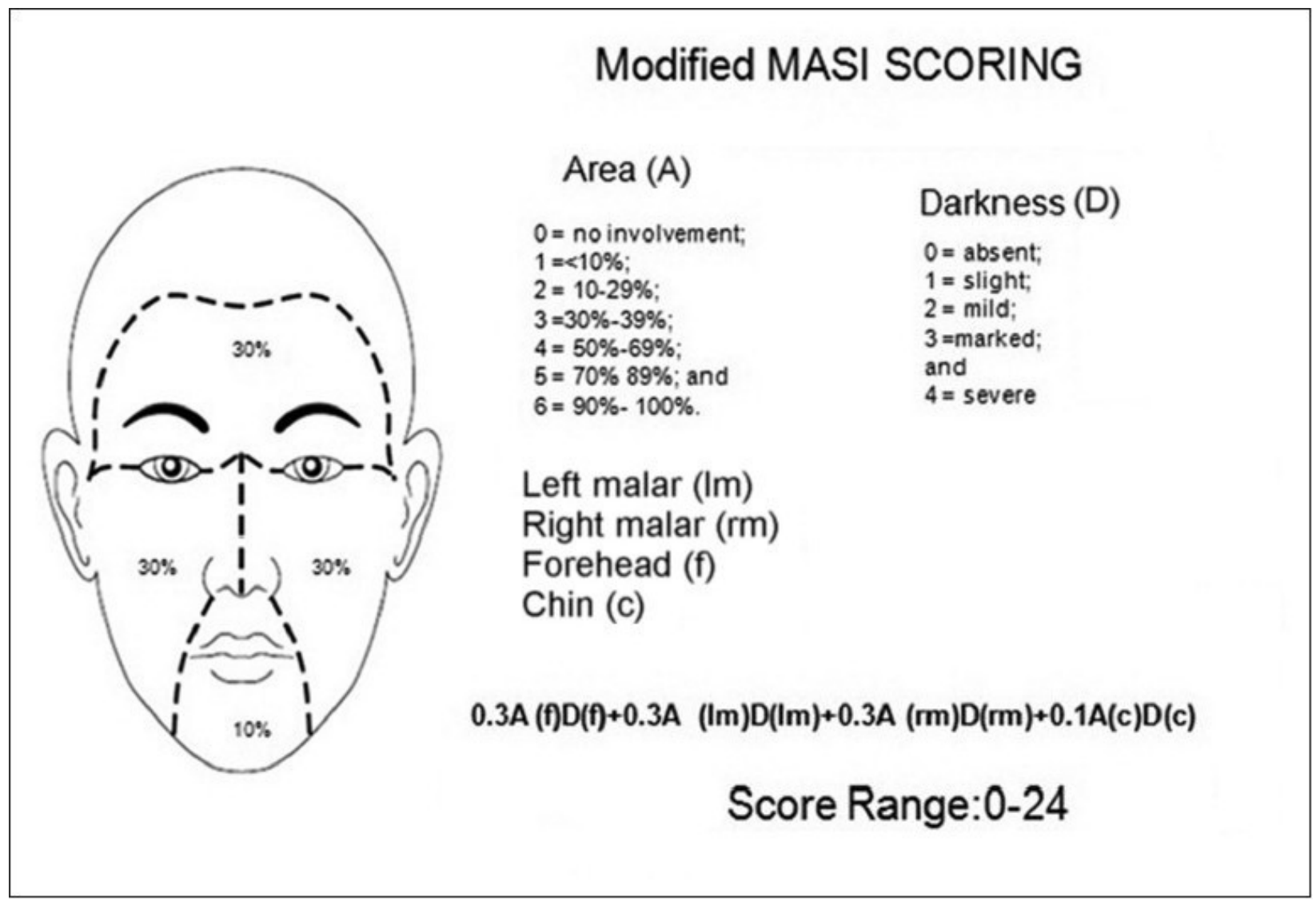

Figure 1: Melasma Area and Severity Index (MASI) (Adapted from Kimbrough-Green et al. (23)

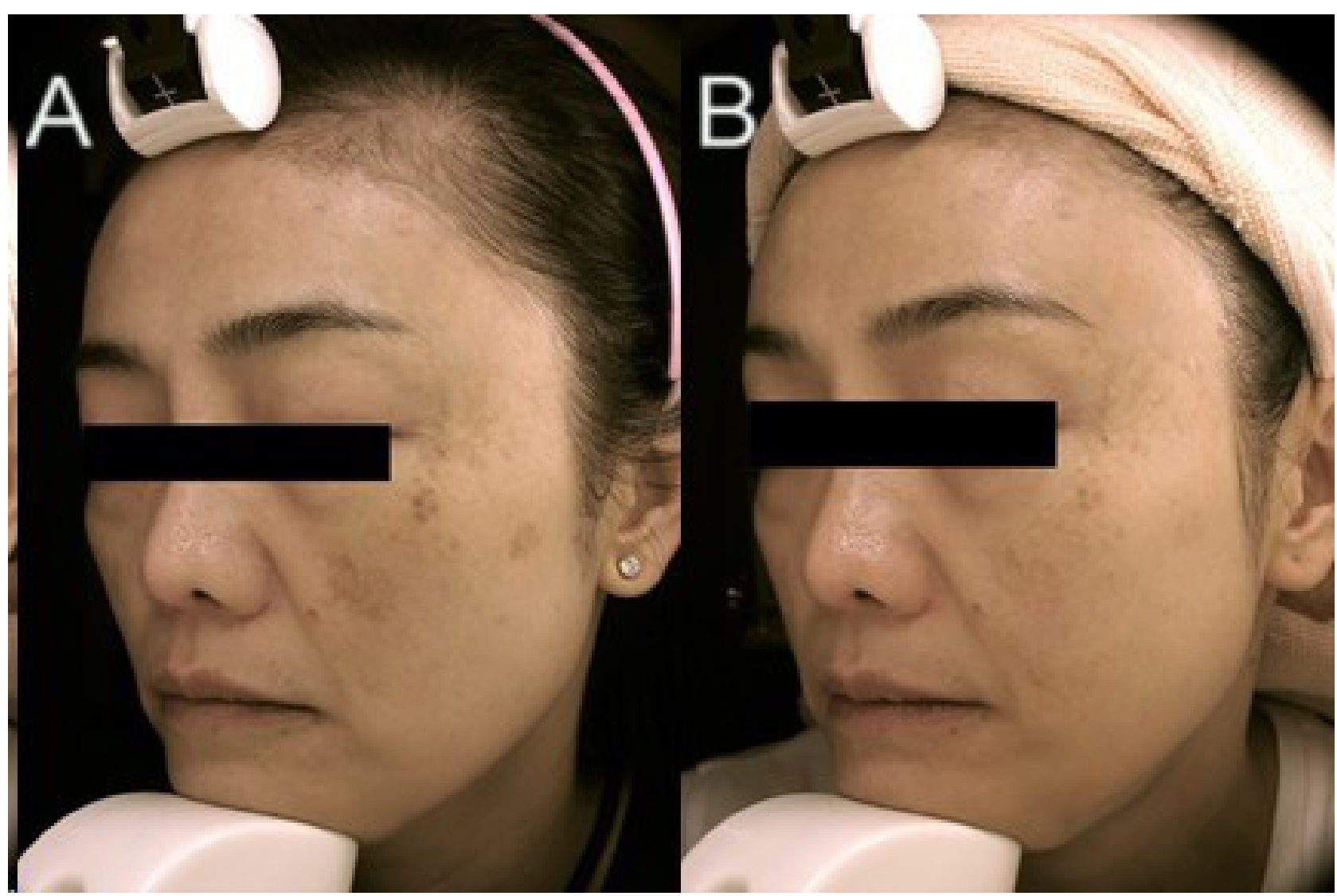

Figure 2: Clinical photograph of case 1 at the baseline (A) and after 6 months follow-up (B) 

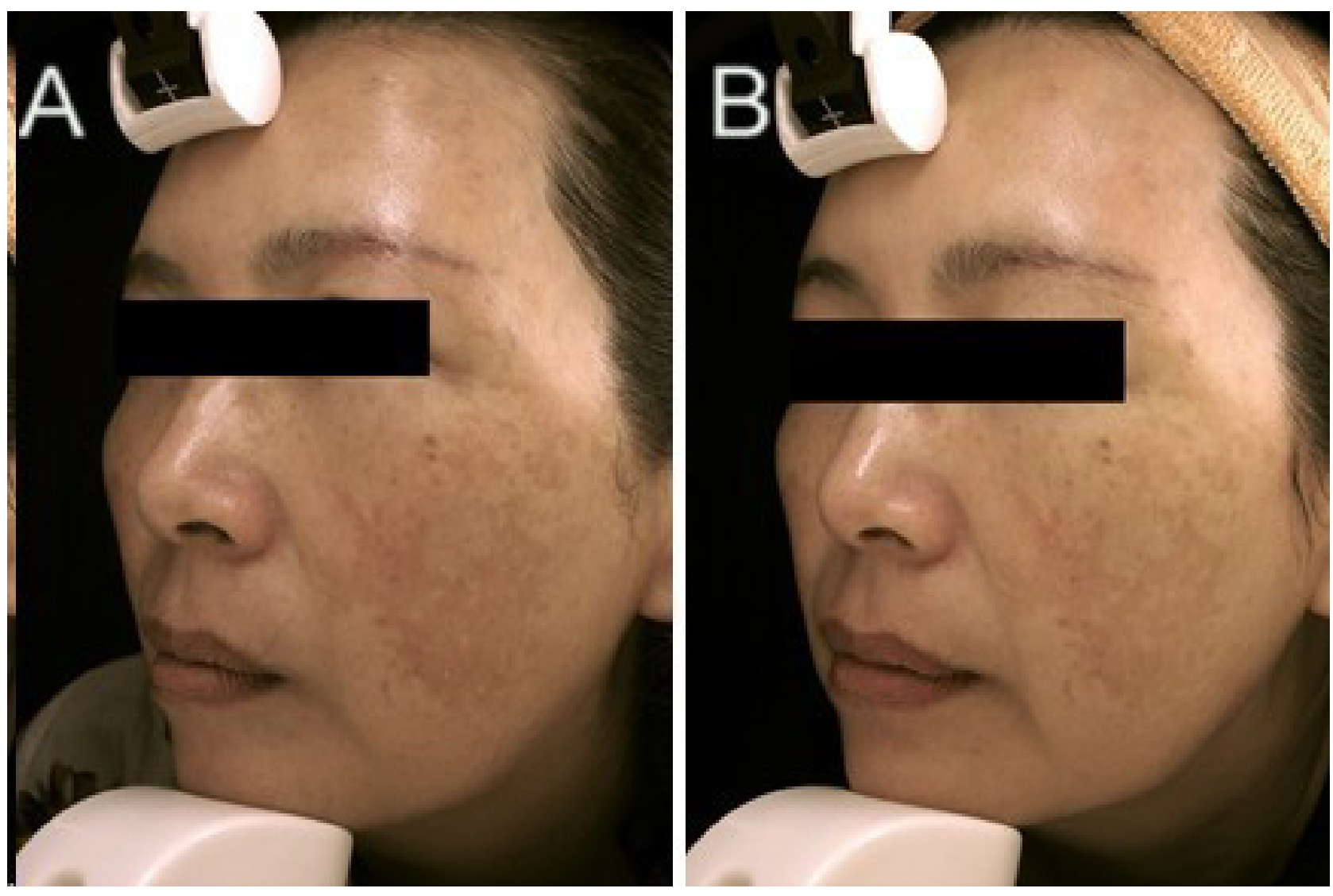

Figure 3: Clinical photograph of case 2 at the baseline (A) and after 6 months follow-up (B)

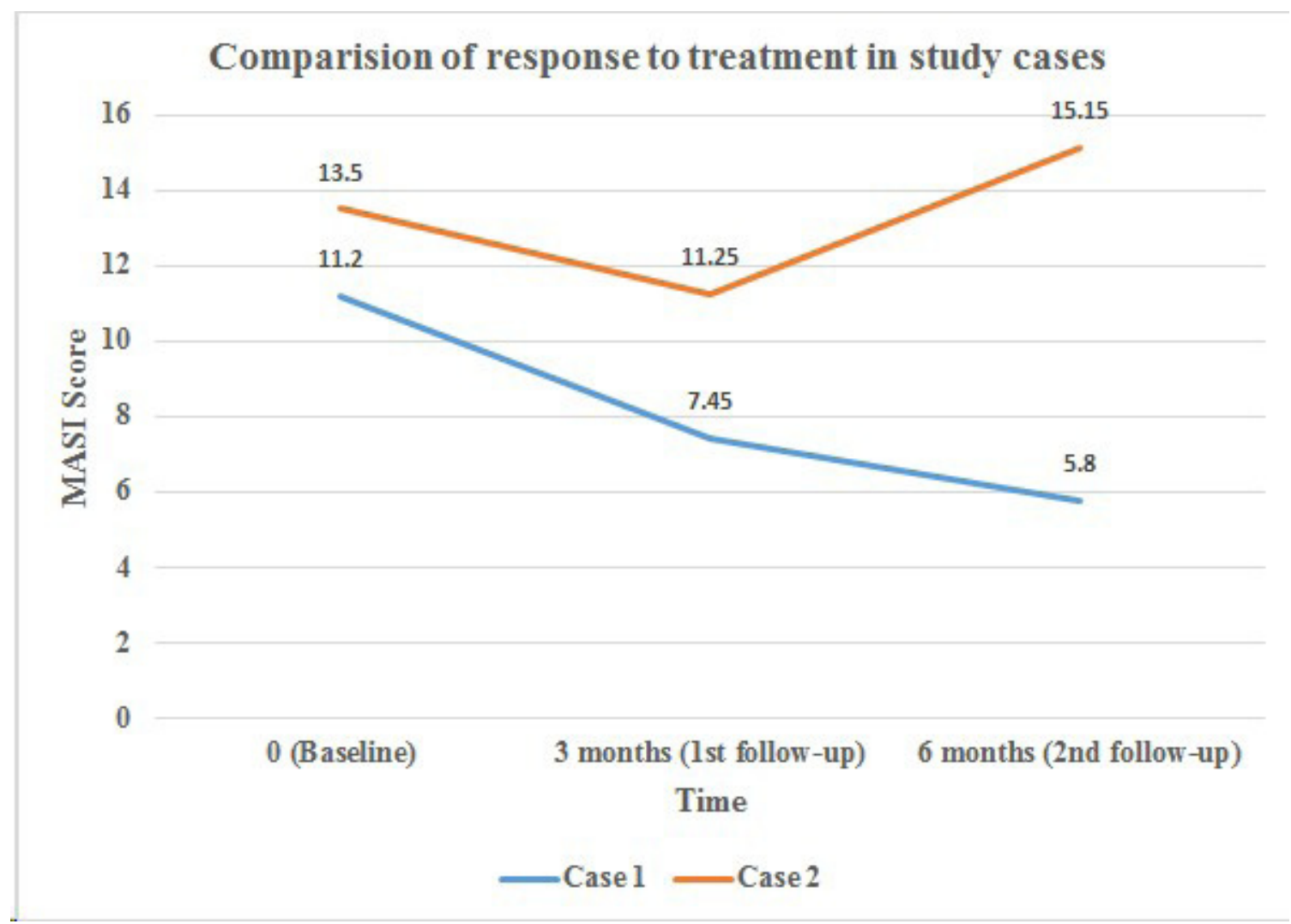

Figure 4: Comparative graph depicting the changes in MASI score in case 1 and 2 


\section{Discussion}

PRP was used in this study as adjunct to the conventional therapies of melasma because PRP has been reported to reduce the pigmentation when it used to treat other skin conditions. For instances, application of PRP was observed to reduce the incidence of post-inflammatory hyperpigmentation; an effect which might be due to PRP exerting a healing of the basement membrane by laminin, collagen IV, and tenascin stimulated by the TGF-b $(24,25)$ found in the PRP.

In this case study, two cases showed different degrees of improvement in MASI score using the same therapy regime by identical operator. In case one, the improvement observed was remarkable, after treatment as well as at the follow up on the $3^{\text {rd }}$ and the $6^{\text {th }}$ months enly minor degree of improvement was observed in case two after treatment, and in case 2, at the 6 months follow up, a rebound of hyperpigmentation was noted. Recurrence of melasma is common even after successful treatment (26).

The divergent response of the two patients to an identical therapy in this study, could be due to a number of factors. Less improvement observed in case 2 could be due to a higher Fitzpatrick skin type and a more severe mixed type melasma with telangiectasia, as has been noted in an earlier report (18). Improvement of the telangiectasia and erythema was noted by the subject herself after the first session of PRP therapy. These might be due to the underlying modulation of angiogenesis by the orchestration of the growth factors released during the PRP therapy. This mechanism is similar to wound healings and would seem to promote appropriate angiogenesis without inducing excessive blood vessels formation.

In addition to its known function of coagulation, platelet may also play a role in the field of aesthetic medicine, for skin rejuvenation. When the platelets are activated by thrombin, calcium or collagen, degranulation of the intracellular alpha-granules of the platelets lead to the release of growth factors such as platelet derived growth factor (PDGF), epidermal growth factor (EGF), vascular endothelial growth factor (VEGF), fibroblast growth factor (FGF) and transforming growth factor-beta (TGF- $\beta$ ) which stimulate the proliferation of fibroblast and epidermal cell, promote angiogenesis and induce collagen synthesis (27).

The improvement of pigmentation after fractional photothermolysis and PRP therapy in one of the cases in this study may be attributed to the release of TGF- $\beta$ which is known to decrease melanogenesis $(25,28)$. TGF- $\beta 1$ is a cytokine involved in cell differentiation, proliferation and apoptosis. There are studies demonstrating that TGF- $\beta 1$ inhibits melanogenesis by the down-regulation of the microphthalmia associated transcription factor (MITF) promoter activity and inhibits the expression of pairedbox homeotic gene (PAX 3), which at the protein level, it reduces the production of tyrosinase, tyrosinase-related protein 1 , tyrosinase-related protein 2 and microphthalmia associated transcription factor (MITF) (29-31). Therefore it is postulated that TGF- $\beta 1$, one of the main cytokines released from platelet rich plasma, would help to reduce the pigmentation of melasma.

The side effects and complications observed in this case study were minimal and tolerable to the subjects with the careful application of local anaesthetic cream, a meticulous injection techniques and an application of the cooling mask or cold compression. At the $6^{\text {th }}$ months follow up, the recurrence or rebound of melasma for subjects 2 was high as the change of the mean MASI score was 53\%, and this was higher than results from other studies (20, 32). This might be due to the loss of inhibitory effects of melanogenesis by PRP therapy with the transient release of platelet growth factor.

\section{Conclusion}

Melasma is common among Asian females and it is resistant to conventional therapies. Our study shows that PRP may serve as a source of different growth factors to reduce the pigmentation, in some cases, acting synergistically with conventional therapy. In this case study, minimal side effects were observed with the intradermal PRP injection, with little pain, erythema, oedema and bruises. This case study can serve as a pilot study for PRP injection, as adjunct to other conventional therapy. It will be more beneficial to the melasma patients if multi-centre studies can be done in with a larger sample size with a control group to evaluate the effect of PRP injection in melasma patients with different skin types.

\section{References}

1. Grimes PE. Melasma: etiologic and therapeutic considerations. Arch Dermatol 1995; 131:1453-7.

2. Werlinger KD, Guevara IL, Gonzalez CM, Rincon ET, Caetano R, Haley RW. Prevalence of self-diagnosed melasma among pre-menopausal Latino women in Dallas and Forth Worth, Tex. Arch Dermatol 2007; 143:424-5.

3. Sivayathorn A. Melasma in orientals. Clin Drug Invest 1995; 10(Suppl. 2):34-63.

4. Sanchez NP, Pathak MA, Sato S, Fitzpatrick TB, Sanchez JL, Mihm MC Jr. Melasma: A clinical, light microscopic, ultra-structural, and immunofluorescence study. J Am Acad Dermatol 1981; 4:698-710.

5. Kang WH, Yoon KH, Lee ES, Kim J, Lee KB. Melasma: histopathological characteristics in 56 Korean patients. Br J Dermatol 2002; 146:228-37.

6. Mosher DB, Fitzpatrick TB, Ortonne J-P, Hori Y. Hypomelanoses and hypermelanoses. In: Fitzpatrick's Dermatology in General Medicine. Vol. 1. New York: McGraw-Hill 1999; 945-1017.

7. Barankin B, Silver SG, Carruthers A. The skin in pregnancy. J Cutan Med Surg 2002; 6:236-40.

8. Kang HY, Hwang JS, Lee JY, Ahn JH, Kim JY, Lee ES. The dermal stem cell factor and c-kit are overexpressed in melasma. Br J Dermatol 2006; 154:1094-9. 
9. Kim EJ, Park HY, Yaar M. Modulation of vascular endothelial growth factor receptors in melanocytes. Exp Dermatol 2005; 14:625-33.

10. Lieberman R, Moy L. Estrogen receptor expression in melasma: results from facial skin of affected patients. J Drugs Dermatol 2008; 7:463-5.

11. Maeda K, Naganuma M, Fukuda M, Matsunaga J, Tomita Y. Effect of pituitary and ovarian hormones on human melanocytes in vitro. Pigment Cell Res 1996; 9:204-12.

12. Vaneeta M. Sheth, Amit G. Pandya. Melasma: A comprehensive update. J Am Acad Dermatol 2011; 65:699-714.

13. Godse KV, Sakhia J. Triple combination and glycolic acid peels in melasma in Indian patients. $J$ Cosmet Dermatol. 2011; 10(1):68-69.

14. Kumari R, Thappa DM. Comparative study of trichloroacetic acid versus glycolic acid chemical peels in the treatment of melasma. Indian J Dermatol Venereol Leprol. 2010; 76(4):447.

15. Polnikorn N. Treatment of refractory dermal melasma with the MedLite C6 Q-switched Nd:YAG laser: Two case reports. J Cosmet Laser Ther. 2008; 10(3):16773.

16. Wattanakrai P, Mornchan R, Eimpunth S. Low-fluence Q-switched neodymium-doped yttrium aluminum garnet $(1,064 \mathrm{~nm})$ laser for the treatment of facial melasma in Asians. Dermatol Surg 2010; 36:76-87.

17. Choi M, Choi JW, Lee SY, Choi SY, Park HJ, Park KC. Low-dose 1064-nm Q-switched Nd:YAG laser for the treatment of melasma. J Dermatolog Treat 2010; 21:224-228.

18. Chan NP, Ho SG, Shek SY, Yeung CK, Chan HH. A case series of facial depigmentation associated with low fluence Q-switched 1,064 nm Nd:YAG laser for skin rejuvenation and melasma. Lasers Surg Med 2010; 42:712-719.

19. Kim MJ, Kim JS, Cho SB. Punctate leucoderma after melasma treatment using 1064-nm Q-switched Nd:YAG laser with low pulse energy. J Eur Acad Dermatol Venereol 2009; 23:960-962.

20. Jeong S, Shin J, Yeo U, Kim W, Kim I. Low-fluence Q-switched neodymium-doped yttrium aluminum garnet laser for melasma with pre- or post-treatment triple combination cream. Dermatol Surg. 2010; 36(6):909-18.

21. Haddad AL, Matos LF, Brunstein F, Ferreira LM, Silva A, Costa D Jr. A clinical, prospective, randomized, double-blind trial comparing skin whitening complex with hydroquinone vs. placebo in the treatment of melasma. Int J Dermatol 2003; 42:153-156.

22. Na JI, Choi JW, Choi HR, J BJ, Park KC, Youn SW, Huh $\mathrm{CH}$. Rapid healing and reduced erythema after ablative fractional carbon dioxide laser resurfacing combined with the application of autologous platelet rich plasma. Dermatol Surg 2011; 37:463-468.

23. Kimbrough-Green CK, Griffiths CE, Finkel L, Hamilton TA, Bulengo-Ransby SM, Ellis CN, et al. Topical retinoic acid for melasma in black patients: a vehiclecontrolled clinical trial. Arch Dermatol 1994; 130:72733.

24. Lacz NL, Vafaie J, Kihiczak NI, et al. Postinflammatory hyperpigmentation: a common but troubling condition. Int J Dermatol 2004; 43:362-5.

25. Tamariz-Dominguez E, Castro-Munozledo F, KuriHarcuch W. Growth factors and extracellular matrix proteins during wound healing promoted with frozen cultured sheets of human epidermal keratinocytes. Cell Tissue Res 2002; 307:79-89.

26. Balkrishnan R, McMichael AJ, Camacho FT. Development and validation of a health-related quality of life instrument for women with melasma. Br J Dermatol 2003; 149:572-7.

27. Rozman P, Bolta Z. Use of platelet growth factors in treating wounds and soft tissue injuries. Acta Dermatovenerol Alp Panonica Adriat 2007; 16:15665.

28. Burd A, Zhu N, Poon VK. A study of Q-switched $\mathrm{Nd}$ :YAG laser irradiation and paracrine function in human skin cells. Photodermatol Photoimmunol Photomed 2005;21:131-7.

29. Solano F, Briganti S, Picardo M, Ghanem, G. Hypopigmenting agents: An updated review on biological, chemical and clinical aspects. Pigment Cell Res 2006; 90:550-571.

30. Kim D, Park S, Park K. Transforming growth factor- $\beta 1$ decreases melanin synthesis via delayed extracellular signal-regulated kinase activation. Int J Biochem Cell Biol 2004; 36:1482-1491

31. Yang G, Li Y, Nishimura E, Xin H, Zhou A, Guo Y, Dong $L$, Denning $M$, Nickoloff $B$, Cui R. Inhibition of PAX3 by TGF- $\beta$ modulates melanocyte viability. Mol. Cell 2008; 32:554-563.

32. Polnikorn N. Treatment of refractory melasma with the MedLite C6 Q-switched Nd:YAG laser and alpha arbutin: a prospective study. Cosmet Laser Ther 2010; 12:126-31. 